\title{
Epidemiological, Clinical and Therapeutic Issues of Epulis at Campus University Teaching Hospital of Lomé: About 33 Cases
}

\author{
Saliou Adam 1,2*, Hamza Dolès Sama ${ }^{3}$, Palokina Agoda ${ }^{4}$, Haréfétéguéna Bissa ${ }^{1,2}$, \\ Winga Foma ${ }^{2}$, Essobozou Plaoudézina Pegbessou ${ }^{5}$, Bathokédéou Amana ${ }^{6}$, \\ Essoham Boko5, Eyawèlohn Kpemissi ${ }^{2}$
}

${ }^{1}$ Department of Stomatology and Maxillofacial Surgery at Sylvanus Olympio University Teaching Hospital of Lomé, Lomé, Togo ${ }^{2}$ Department of ENT at Sylvanus Olympio University Teaching Hospital of Lomé, Lomé, Togo

${ }^{3}$ Department of Anesthesia and Intensive Care at Sylvanus Olympio University Teaching Hospital of Lomé, Lomé, Togo

${ }^{4}$ Department of Stomatology at Campus University Teaching Hospital of Lomé, Lomé, Togo

${ }^{5}$ Department of ENT at Campus University Teaching Hospital of Lomé, Lomé, Togo

${ }^{6}$ Department of ENT at Regional Hospital of Lomé, Lomé, Togo

Email: *saliou.adam1@yahoo.com

How to cite this paper: Adam, S., Sama, H.D., Agoda, P., Bissa, H., Foma, W., Pegbessou, E.P., Amana, B., Boko, E. and Kpemissi, E. (2019) Epidemiological, Clinical and Therapeutic Issues of Epulis at Campus University Teaching Hospital of Lomé: About 33 Cases. Open Journal of Stomatology, 9, 168-174. https://doi.org/10.4236/ojst.2019.97017

Received: May 30, 2019

Accepted: July 7, 2019

Published: July 10, 2019

Copyright ( 2019 by author(s) and Scientific Research Publishing Inc. This work is licensed under the Creative Commons Attribution International License (CC BY 4.0).

http://creativecommons.org/licenses/by/4.0/ (c) (i) Open Access

\begin{abstract}
Introduction: The epulis is a hyperplastic tumor-like of the gingival or cheek mucosa that would be due to inflammatory reactions. Its pathogenesis remains incompletely understood. It appears to be common in Africa, but no study has been conducted in Togo. Our purpose was to describe epidemiological, clinical and therapeutic aspects of the epulis at the Campus University Teaching Hospital in Lomé. Patients and methods: This was a retrospective descriptive study on 33 cases at the Odontostomatology Department, from January 1st, 2014 to December 31st, 2016. Results: The prevalence of epulis was $0.88 \%$. The average age of the patients was 36.92 years old. The most affected age group was 20 - 29 years old $(30.30 \%)$. The sex ratio was 0.57 . Low education and poor socio-economic conditions were found to be predisposing factors. Mucous swelling was the main reason for consultation. A local irritative factor was found in more than half of the cases. The preferred seat was gum (63.63\%). Inflammatory epulis was found in $36.36 \%$ of cases. Biopsy-excision was performed in $96.96 \%$ of patients, with a cure without sequelae in $100 \%$. Conclusion: The epulis is a rare benign affection of the gum. Its favoring factors are mechanical or infectious local irritation, or hormonal factors. His diagnosis is essentially clinical, but requires histological confirmation to distinguish it from other serious tumors. Biopsy-excision is the main treatment. No sequelae are observed in all patients of our series.
\end{abstract}




\section{Keywords}

Epulis, Epidemiology, Clinic, Treatment, Togo

\section{Introduction}

The epulis is a hyperplastic tumor-like of the gingival or cheek mucosa that is thought to be secondary to inflammatory reactions responding to an iterative irritative phenomenon. If the inflammatory cause is irrefutable, some authors suggest the involvement of the host factor. However, its pathogenesis remains incompletely elucidated [1] [2]. The epulis is characterized at the beginning by an absence of symptomatology, making the consultation late especially in African environment. In the absence of treatment, it can lead to a large volume that aggravates a functional or aesthetic discomfort. The epulis may progress to complications such as alveolysis or chronic bleeding. The diagnosis of the epulis is generally easy clinically. It is the histological examination that will allow an accurate diagnosis and can eliminate other benign or malignant tumors. Surgery remains the method of choice for the treatment of epulis. Other physical means are recommended, mainly cryotherapy and laser [3] [4]. The ligation of the pedicle of the tumor is sometimes used to prevent its vascularization, thus causing its necrosis and its fall. Radiation therapy is rarely used. Medical means such as antibiotics can be used for prophylaxis or in case of superinfection of the tumor. The evolution is towards healing after total surgical excision. In case of incomplete treatment, the tumor-like may reoffend. There is little literature in Africa [5] [6]. No studies have yet been conducted in Togo, although oral health is of major public health interest [7]. The purpose of the present work was to carry out an epidemiological, clinical and therapeutic study of the epulis at the University Teaching Hospital Campus (CHU-Camus) of Lomé.

\section{Patients and Method}

We carried out a descriptive retrospective study over a period of 3 years (January 2014 to December 2016) on the individual files of patients received for the epulis and the consultation records of the department. A pre-designed survey sheet allowed the collection of data. The main variables studied were sex, age, socio-economic level of patients, clinical signs, etiological factors, para-clinical examinations, diagnosis, and treatment. We included in our study the patients who consulted for the epulis (hyperplastic tumor-like of gingival or cheek mucosa) during our study period and whose files contained the information retained on our survey sheet, quoted above. We excluded from our study all patients who consulted for any other condition (Malignant tumor of oral cavity, abscess, and all other tumors) and those whose records were incomplete (age, sex not mentioned, etc.). The collected data were processed and analyzed by EPI INFO version 7 software, World 2010 software and Excel 2010 software. Our study was 
conducted in the Stomatology department of the University Teaching Hospital Campus (CHU-Campus) of Lomé. It is one of the two University teaching hospitals in Lomé, the capital of Togo. It provides health care, training and research activities in health sciences. It has two dental surgeons, one specialized in oral surgery, two senior technicians in Stomatology, a state-certified nurse serving as a supervisor of the department, two nurse assistants, a panoramic and retro-alveolar $\mathrm{X}$-Ray manipulator, one nurse and one administrative secretary. The service includes three dental offices, three dental surgeon's offices, a medical-surgical equipment room, a sterilization room, a panoramic and retro-alveolar X-ray room, a practical lab for students, secretary office and a technical platform suitable for consultation and medico-surgical care.

\section{Results}

During our study period, 3751 patients had consulted in the Stomatology Department of the CHU-Campus. Among them, we kept records of 33 patients treated for epulis, then a hospital frequency of $0.9 \%$. The average age of patients in our series was 36.9 years with extremes of 4 years and 75 years. The most represented age group was $20-29$ years $(\mathrm{N}=10)$, or $30.3 \%$. Twelve patients in our series were male versus 21 female, a sex ratio of 0.6 . Twenty patients had a primary level. Only 3 patients had a university level. Eight patients were housewives, $24.2 \%$. Thirty-one patients in our series were Togolese (93.9\%). The largest proportion of our patients came from the city of Lomé $(\mathrm{N}=16)$, or $48.5 \%$.

Tumor was the main reason for consultation $(\mathrm{N}=15)$, or $45.5 \%$, followed by swelling associated with functional impairment $(\mathrm{N}=9)$, or $27.3 \%$. The wearing of poorly fitting dental prosthesis was the most represented irritant factor $(\mathrm{N}=$ 8 ), or $27.3 \%$, followed by tartaric gingivitis $(\mathrm{N}=7)$, or $24.2 \%$. Etiological factors are reported in Table 1.

Table 2 showed the distribution of the patients of our study by socio-demographic characteristics. Housewife was the main representative category (24.24\%), followed by merchant (15.15\%) and pupils (12.12\%).

Ten and eight patients consulted 24 months after the onset of symptoms. The

Table 1. Distribution of cases by etiological factors.

\begin{tabular}{ccc}
\hline Etiological factors & Cases & Percentage \\
\hline Wearing poorly fitting dental prostheses & 9 & $\mathbf{2 7 . 2 7}$ \\
Presence of tartar blocks (tartaric gingivitis) & 8 & 24.24 \\
Tartar blocks + rootstock & 5 & 15.15 \\
Partial indentation not rehabilitated & 5 & 15.15 \\
Foreign body in the alveolar bone (post-extraction) & 3 & 9.10 \\
Congenital formation & 2 & 6.06 \\
Pregnancy & 1 & 3.03 \\
Total & 33 & 100.00 \\
\hline
\end{tabular}


Table 2. Distribution of cases by sociodemographic characteristics.

\begin{tabular}{ccc}
\hline Occupation & Cases & Percentage \\
\hline Housewife & $\mathbf{8}$ & 24.24 \\
Agent at port & 1 & 3.03 \\
Farmer & 3 & 9.09 \\
Apprentice & 1 & 3.03 \\
Dressing & 1 & 3.03 \\
Merchant & 5 & 15.15 \\
Motorcycle taxi driver & 1 & 3.03 \\
Seamstress & 3 & 9.09 \\
Pupil & 4 & 12.12 \\
Teacher & 1 & 3.03 \\
Student & 2 & 6.07 \\
IT & 1 & 3.03 \\
Joiner & 1 & 3.03 \\
Military & 1 & 3.03 \\
Total & 33 & 100.00 \\
\hline
\end{tabular}

gingival mucosa $(\mathrm{N}=21)$, or $63.6 \%$, was the preferred seat of the epulis in our series, followed by the mucous membranes of cheek $(\mathrm{N}=4)$, and lip $(\mathrm{N}=4)$, i.e. $12.1 \%$ each. Pediculated implantation was the most represented $(\mathrm{N}=28)$, with $84.8 \%$, followed by sessile $(\mathrm{N}=5)$, or $15.2 \%$. There were: $36.4 \%$ inflammatory epulis, 27.3\% fibro inflammatory epulis, 27.3\% fibrous epulis and 9.1\% giant cell epulis. Only eight of the 33 patients in our series had performed the orthopantomogram X-Ray, or $24.24 \%$. Thirty-two cases of epulis (Figure 1) underwent surgical biopsy-resection (Figure 2) under local anesthesia, or $97 \%$. Therapeutic abstention was observed in one patient (pregnant woman). Postoperatively, all patients received antalgic treatment, antibiotic prophylaxis and local antiseptic care. Of the $97 \%$ of patients who had undergone surgical treatment (biopsy-excision), no case of recurrence had been observed, no complication, and no sequelae after six months postoperative.

\section{Discussion}

The prevalence of epulis in our series was $0.9 \%$. This prevalence would be underestimated because of incomplete records not included in our study and the relative rarity of this condition found in the literature [6]. The most affected age group in our study was young adults (20 - 29 years old) with a frequency of $30.3 \%$. In our study females were predominant with a sex ratio of 0.6. Indeed, according to several studies the epulis would be an affection that affects the woman more than the man. This trend could be explained by the strong impregnation and hormonal variations during the period of female genital activity 


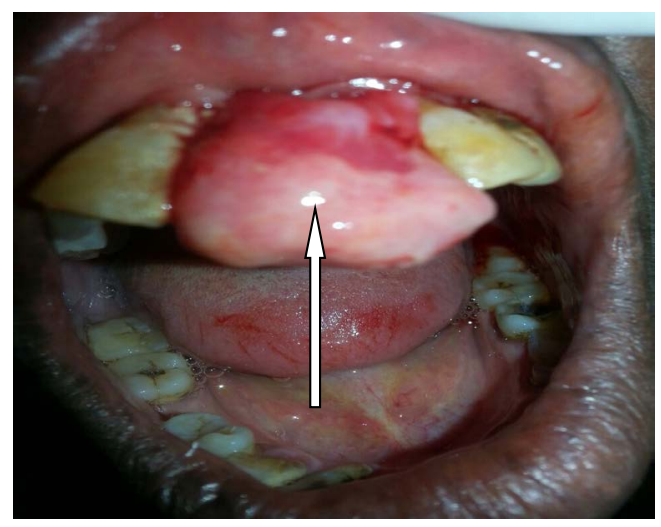

Figure 1. Epulis.

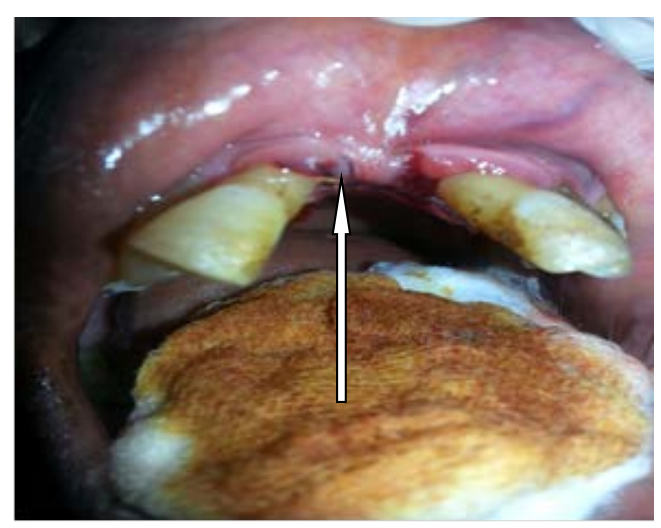

Figure 2. Mouth cavity after biopsy-excision.

[8]. The low level of knowledge of oral hygiene measures, the resulting tooth decay can lead to extractions affected teeth and then the possible installation of dental appliances which, if they are not adapted, could lead to epulis as well as the constitution of dental plates [9] [10] [11] [12] [13]. The main reason for consultation in our study was swelling ( $45.5 \%$ of cases). The swelling appears as a functional disorder because of the discomfort to chewing it can cause or because of the aesthetic impact related to its volume. Our study revealed that the etiological factor most involved in the occurrence of the epulis was the irritative factor with in particular the wearing of poorly adapted dental prosthesis in $27.3 \%$ of cases and tartaric gingivitis in $24.2 \%$ of cases. This result is consistent with the etiopathogenesis of the epulis, which is described as a hyperplastic tumor-like related to inflammatory reactions responding to iterative irritative phenomena [6] [12]. However, some authors have reported that the epulis is linked to metaplasia of the connective tissue; blood-sacrament disorders or general pathologies have been reported [14] [15]. The preferred seat of the epulis was the gingival mucosa in $63.6 \%$ of cases. These results of our series could be explained in part by the fact that poorly adapted prostheses are based on the gingival fibro-mucosa causing local irritation [12]. In our study, patients consulted after more than 24 months of their lesion evolution in more than half of cases $(54.54 \%)$. This late consultation could be explained by the asymptomatic 
nature of the lesion at the beginning, notably the absence of pain. And it is only the occurrence of functional and/or aesthetic discomfort during the course of the evolution that often leads patients to consult. The use of traditional treatment, self-medication, ignorance and a poor understanding of this pathology are additional reasons that would explain the delay in consultation in our context. Inflammatory epulis was the main histological form in our series (33.3\%). a review of the literature reveals the existence of several forms of epulis including inflammatory, fibro-inflammatory, angiomatous, and giant cell or myeloplax forms [16] [17]. The realization of a radiological examination is not essential in the diagnostic or therapeutic approach of the epulis. However, this imaging is sometimes required to assess possible alveolar bone involvement or eliminate an underlying bone tumor. Biopsy-excision was the treatment of choice in our series with $97 \%$ of cases. One hundred percent of our patients had a cure without sequelae. Incomplete resection carries a risk of local recurrence of the tumor-like [2]. Therapeutic abstention was observed in one patient of our series carrying a pregnancy. This therapeutic abstention was observed because of the sometimes regressive nature of this affection after delivery [8]. Of the $97 \%$ of patients who had undergone surgery-type biopsy-resection, there was no evidence of recurrence.

\section{Conclusion}

The epulis is a rare benign affection whose seat of predilection is gum. The main contributing factors are mechanical or infectious local irritation, or hormonal factors. His diagnosis is clinical, based on pedicle or sessile gingival swelling, but requires histological confirmation. Biopsy-excision is the treatment of choice, with a cure without sequelae in all the patients of our series.

\section{Conflicts of Interest}

The authors declare no conflicts of interest regarding the publication of this paper.

\section{References}

[1] Gawron, K., Bereta, G., Nowakowska, Z., Łazarz-Bartyzel, K., Potempa, J., Chomyszyn-Gajewska, M., Górska, R. and Plakwicz, P. (2017) Analysis of Mutations in the SOS-1 Gene in Two Polish Families with Hereditary Gingival Fibromatosis Oral Diseases, 23, 983-989. https://doi.org/10.1111/odi.12684

[2] Gawron, K., Łazarz-Bartyzel, K., Potempa, J. and Chomyszyn-Gajewska, M. (2016) Gingival Fibromatosis: Clinical, Molecular and Therapeutic Issues. Orphanet Journal of Rare Diseases, 11, 9. https://doi.org/10.1186/s13023-016-0395-1

[3] Kinane, D.F., Stathopoulou, P.G. and Papapanou, P.N. (2017) Periodontal Diseases. Nature Reviews Disease Primers, 3, Article No. 17038. https://doi.org/10.1038/nrdp.2017.38

[4] Jha, N., Ryu, J.J., Wahab, R., Al-Khedhairy, A.A., Choi, E.H. and Kaushik, N.K. (2017) Treatment of Oral Hyperpigmentation and Gummy Smile Using Lasers and Role of Plasma as a Novel Treatment Technique in Dentistry: An Introductory Re- 
view. Oncotarget, 8, 20496-20509. https://doi.org/10.18632/oncotarget.14887

[5] Traore, H., Kamissoko, K., Traore, D., Coulibali, A.D., Théra, T.D. and Touré, K. (2013) Epulis Fibreuse Remaniée: Prise en charge chirurgicale d'un cas. Mali Medical, 53, 45-48.

[6] Elmahi, H. and Mernissi, F.Z. (2016) Multiples épulis. The Pan African Medical Journal, 25, 15. https://doi.org/10.11604/pamj.2016.25.15.10626

[7] Marcenes, W., Kassebaum, N.J., Bernabé, E., Flaxman, A., Naghavi, M., Lopez, A. and Murray, C.J.L. (2013) Global Burden of Oral conditions in 1990-2010: A Systematic Analysis. Journal of Dental Research, 92, 592-597. https://doi.org/10.1177/0022034513490168

[8] Karande, V. and Andrade, N.N. (2018) Juvenile Hyaline Fibromatosis. Contemporary Clinical Dentistry, 9, 484-487.

[9] Agbaje, H.O., Kolawole, K.A., Folayan, M.O., Onyejaka, N.K., Oziegbe, E.O., Oyedele, T.A., Chukwumah, N.M. and Oshomoji, O.V. (2016) Digit Sucking, Age, Sex, and Socioeconomic Status as Determinants of Oral Hygiene Status and Gingival Health of Children in Suburban Nigeria. Journal of Periodontology, 87, 1047-1056. https://doi.org/10.1902/jop.2016.150681

[10] Okoh, M. and Enabulele, J. (2014) Influence of Clinical Experience on Oral Health Attitude and Behaviour of Dental Students Attending a Nigerian University. Odontostomatol Trop, 37, 25-31.

[11] Owino, R.O., Masiga, M.A., Ng'ang'a, P.M. and Macigo, F.G. (2010) Dental Caries, Gingivitis and the Treatment Needs among 12-Year-Olds. East African Medical Journal, 87, 25-31. https://doi.org/10.4314/eamj.v87i1.59950

[12] Mohan, R.P.S., Verma, S., Singh, U. and Agarwal, N. (2013) Epulis Fissuratum: Consequence of Ill-Fitting Prosthesis. BMJ Case Reports, 2013, bcr2013200054. https://doi.org/10.1136/bcr-2013-200054

[13] Azodo, C.C. and Agbor, A.M. (2015) Gingival Health and Oral Hygiene Practices of Schoolchildren in the North West Region of Cameroon. BMC Research Notes, 8, 385. https://doi.org/10.1186/s13104-015-1350-2

[14] Karim, E.K., Alae, G., Farah, H., Hicham, S., Abderrahman, A.B. and Abdelkader, R. (2011) Tumeurs bénignes de la cavité buccale: Étude rétrospective de 209 cas. Medecine Buccale Chirurgie Buccale, 17, 115-119.

[15] Beaumont, J., Chesterman, J., Kellett, M. and Durey, K. (2017) Gingival Overgrowth: Part 1: Aetiology and Clinical Diagnosis. British Dental Journal, 222, 85-91. https://doi.org/10.1038/sj.bdj.2017.71

[16] Stephenson, K.A., Klopper, G.J., Opperman, J. and Favara, C. (2017) Giant Maxillary Gingival Fibromatosis. Annals of the Royal College of Surgeons of England, 99, e69-e71. https://doi.org/10.1308/rcsann.2016.0333

[17] Upadhyaya, J.D., Cohen, D.M., Islam, M.N. and Bhattacharyya, I. (2018) Hybrid Central Odontogenic Fibroma with Giant Cell Granuloma Like Lesion: A Report of Three Additional Cases and Review of the Literature. Head and Neck Pathology, 12, 166-174. https://doi.org/10.1007/s12105-017-0845-7 